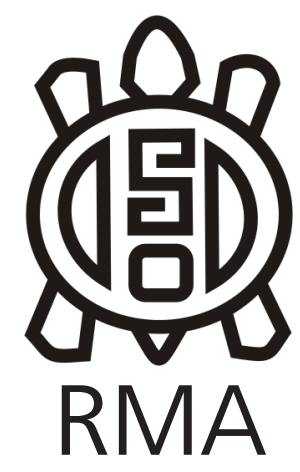

Museología

\title{
Minería, patrimonio cultural y público visitante
}

\author{
Mining, cultural heritage and visiting public
}

\author{
María Eugenia Conforti*, María Vanesa Giacomasso**, María Gabriela \\ Chaparro***, Griselda Lemiez $^{* * * *}$, Micaela María Baier**** y \\ María Luz Endere*****
}

\begin{abstract}
*María Eugenia Conforti, CONICET, Instituto de Investigaciones Arqueológicas y Paleontológicas del Cuaternario Pampeano, Programa Interdisciplinario de Estudios del Patrimonio. Facultad de Ciencias Sociales, Universidad Nacional del Centro de la Provincia de Buenos Aires. E-mail: mariaeugeniaconforti@gmail.com
\end{abstract}

**María Vanesa Giacomasso. CONICET, Instituto de Investigaciones Arqueológicas y Paleontológicas del Cuaternario Pampeano, Programa Interdisciplinario de Estudios del Patrimonio. Facultad de Ciencias Sociales, Universidad Nacional del Centro de la Provincia de Buenos Aires. E-mail: vanegiaco05@gmail.com

***María Gabriela Chaparro. CONICET, Instituto de Investigaciones Arqueológicas y Paleontológicas del Cuaternario Pampeano, Programa Interdisciplinario de Estudios del Patrimonio. Facultad de Ciencias Sociales, Universidad Nacional del Centro de la Provincia de Buenos Aires. E-mail: chaparro@soc.unicen.edu.ar

****Griselda Lemiez. CONICET, Instituto de Investigaciones Arqueológicas y Paleontológicas del Cuaternario Pampeano, Programa Interdisciplinario de Estudios del Patrimonio. Facultad de Ciencias Sociales, Universidad Nacional del Centro de la Provincia de Buenos Aires. E-mail: griseldalemiez@hotmail.com

**** Micaela Baier. Facultad de Ciencias Sociales, Universidad Nacional del Centro de la Provincia de Buenos Aires. E-mail: micaelabaier@gmail.com

*****María Luz Endere. CONICET, Instituto de Investigaciones Arqueológicas y Paleontológicas del Cuaternario Pampeano, Programa Interdisciplinario de Estudios del Patrimonio. Facultad de Ciencias Sociales, Universidad Nacional del Centro de la Provincia de Buenos Aires. E-mail: mendere@soc.unicen.edu.ar

\begin{abstract}
Resumen
En este artículo se presenta un análisis sobre las opiniones del público visitante de la exhibición "ADN Olavarría. Raíces Mineras", vinculada con la historia minera local y que constituye parte de su patrimonio cultural. Dicha propuesta fue realizada en 2018, en la ciudad de Olavarría, provincia de Buenos Aires, en el marco por los festejos del centenario del primer despacho de cemento Portland de Argentina. Se realizó un relevamiento a partir de encuestas semiestructuradas a más de 100 visitantes. Los principales resultados demuestran un desconocimiento general del público sobre los orígenes de la actividad minera local y un reconocimiento de otros aspectos de la identidad olavarriense como constitutivos de su "ADN". Este estudio habilitó una discusión basada en cuatro ejes principales: la interpretación del patrimonio desde la museografía, la rol que le asignó el gobierno local a los investigadores y especialistas, la activación verticalista del repertorio patrimonial local y el rol de los investigadores como activadores de procesos de puesta en valor del patrimonio cultural de Olavarría.
\end{abstract}

Palabras Clave: Minería; Patrimonio cultural; Exhibición pública; Valoraciones; Visitantes.

\begin{abstract}
This paper presents an analysis on the visitors opinion survey of the exhibition "DNA Olavarría. Mining Roots", linked to local mining history as a constituting part of its cultural heritage. It took place in 2018, in the city of Olavarría, Buenos Aires province, within the framework of the centenary celebrations of the first Portland cement dispatch in Argentina. A semi-structured surveys was carried out and more than 100 visitors were interviewed. The main results demonstrate a general ignorance of the public on the origins of local mining activity and a recognition of other aspects of the local identity as constitutive of its "DNA". This study enabled a discussion based on four main axes: the interpretation of heritage from museography, the role that local government gave to researchers and specialists, the up-down activation of the local heritage repertoire, and the role of researchers as activators of processes to enhance the cultural heritage of Olavarría.
\end{abstract}

Keywords: Mining; Cultural heritage; Public exhibition; Valuations; Visitors. 


\section{Introducción}

El partido de Olavarría, ubicado en el centro geográfico de la provincia de Buenos Aires, Argentina, integra el Sistema Serrano de Tandilia cuya antigüedad se remonta a unos 2.200 millones de años, constituyéndose así en una de las formaciones más antiguas de la tierra (Cingolani et al. 2002). Los afloramientos de esta zona incluyen rocas tales como granito, cuarcita, piedra caliza, ftanita, dolomía y arcillas (Figura 1).

Estas características geológicas conforman un paisaje minero particular que ha sido re-utilizado a lo largo del Holoceno ${ }^{1}$ como un recurso valioso para los diferentes habitantes del territorio. Los primeros indicios de interacción entre las poblaciones humanas y estos recursos naturales corresponden a sitios arqueológicos en los cuales se extrajeron materias primas líticas para confeccionar diversas herramientas y armas tales como puntas de proyectil, boleadoras, raederas y cuchillos (Messineo y Barros 2009). Cabe destacar que en la región pampeana argentina los recursos rocosos se encuentran muy localizados y por ello los grupos indígenas cazadoresrecolectores se movilizaban desde lugares distantes hasta este territorio para su abastecimiento.

En la segunda mitad del siglo XIX, con la conquista y ocupación del territorio por parte del naciente gobierno nacional, se comienzan a conformar los primeros poblados que, junto con el aporte de los inmigrantes europeos, impulsaron la explotación minera comercial de Olavarría. Producción que diera origen a una de las principales actividades que, realizadas de manera constante y agiornándose al ritmo del desarrollo tecnológico de cada época, fue marcando una impronta local distintiva en la región, que se extiende hasta nuestros días. En términos de Paz (2009), las etapas productivas mineras se constituyen en dos grandes momentos de la historia olavarriense. El primero de ellos corresponde a la denominada "Etapa proto-industrial" (1860-1917), y está vinculada principalmente a la extracción y producción de tipo más artesanal y mecánica de cal y granito (canteras y caleras). En este momento comienzan a asentarse las poblaciones en las localidades serranas del partido, con un alto número de inmigrantes europeos portadores de las técnicas del oficio minero que se transmitían oralmente y requerían principalmente de fuerza humana, tal es el caso de los picapedreros. El segundo momento se inició en 1919 con la instalación de la primera planta de cemento y fue denominado "Estadio de complejidad tecnológica y productiva o industrial profesional de fábrica" (Paz 2009: 285). Cabe destacar que los recursos naturales disponibles en las sierras del partido resultaron materias primas óptimas y necesarias para la posterior industria del cemento. Este sistema de producción llegó a su auge con la instalación de tres importantes

\footnotetext{
1 Época geológica que abarca desde los 10.000 años Antes del Presente (AP) hasta la actualidad.
}

empresas asentadas en el partido: la Compañía Argentina de Cemento Portland en Sierras Bayas en 1919, Loma Negra S.A en 1928 y Calera Avellaneda S.A en 1932 (Belini 2009). Las dimensiones que alcanzó este modelo, sumado a la permanente demanda del producto, derivó en la necesidad de atraer y fijar a un número mayor de empleados ${ }^{2}$. De esta forma se inicia la instalación de un sistema de villas obreras, aledañas a las plantas industriales, donde vivían los trabajadores y sus familias, recibiendo múltiples beneficios, tales como el préstamo de una vivienda y gratuidad en los servicios vinculados a salud, educación y recreación (Neiburg 1988).

No obstante, los modelos empresariales de fábrica con villa obrera, perecieron en la década de 1980, dejando una huella identitaria en la ciudad de Olavarría, principalmente en quienes además de participar en la producción, fueron habitantes y vecinos de estas villas. En esa década las empresas pasaron a formar parte de capitales multinacionales, complejizaron la tecnología utilizada, prescindiendo de gran cantidad de mano de obra, siempre con el fin de optimizar la producción de cemento a partir de la materia prima local (Lemiez 2018).

Actualmente, "la actividad minera constituye a Olavarría como el principal centro minero de la provincia de Buenos Aires" (Municipalidad de Olavarría 2016:10) ${ }^{3}$ (Figura 2). Además, este desarrollo ha dado lugar a un patrimonio industrial diverso constituido no sólo por los vestigios materiales de los distintos centros productivos que existieron a lo largo de la historia, sino también por un importante bagaje inmaterial que le ha dado una impronta identitaria particular, producto de la dinámica de las nuevas clases sociales vinculadas a las diversas culturas productivas (Paz 2009; ICOMOS-TICCIH 2003). Este conjunto constituye una importante base y un punto de partida para evaluar, conservar, interpretar, financiar y gestionar este "complejo acervo de las culturas industriales" que, como señalan Alfrey y Putman (1992: 64) "debe hacerse haciendo frente a las diversas necesidades, no sólo de los objetos sino de las sociedades que los produjeron".

En este marco, en el mes de febrero del año 2019 se cumplió el centenario del primer despacho de cemento portland de Argentina, realizado desde la planta ubicada en la localidad de Sierras Bayas. Este acontecimiento se ha constituido en un importante hito a nivel local, ya que reivindica la preponderancia, histórica y actual,

\footnotetext{
2 A lo largo del texto se utilizará el masculino a los fines de facilitar su lectura, sin que esto deba ser interpretado como un sesgo de lenguaje sexista.

3 Se trata de un sector muy dinámico, los datos de 2019 (fecha en que se realizó la exhibición) reconocen que "el distrito minero de Olavarría se compone de: 4 Fábricas cemento y cal hidráulica, 4 Fábricas de cal hidráulica, 2 Fábricas de pisos y ladrillos cerámicos, 11 Empresas extracción y trituración de granito, 6 Empresas extracción y trituración de dolomita, 5 Empresas de extracción y trituración de arcillas, 2 Empresas de extracción granito en bloque" (Secretaria de Desarrollo Económico, Dirección de Minería 2018: 4).
} 


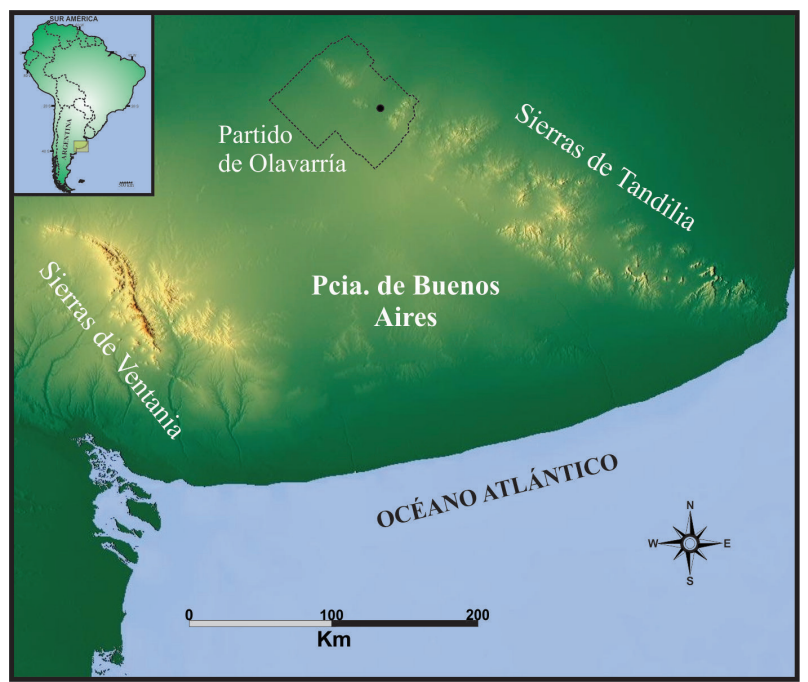

Figura 1. Mapa de la ubicación del Partido de Olavarría.

Figure 1. Map of the location of the Olavarría Party.

de la actividad minera industrial del partido. Por ello se sucedieron una serie de actividades conmemorativas para ponerla en valor (Conforti et al. 2020).

Entre los múltiples festejos efectuados en vísperas del centenario, la Municipalidad de Olavarría decidió organizar una exhibición itinerante que se denominó "ADN Olavarría. Raíces Mineras"4, en la cual se propuso "un recorrido desde los orígenes de los olavarrienses hasta la actualidad, a través de sus actividades productivas mineras, con el objetivo de poner en valor el patrimonio histórico e industrial local"5. Para su organización, en un momento inicial, los gestores se asociaron con empresarios del rubro. Luego, en la etapa de la definición de los contenidos de los paneles a exhibir, el Municipio, a través de la Secretaría de Desarrollo Económico, solicitó el asesoramiento y la colaboración de la Facultad de Ciencias Sociales de la Universidad Nacional del Centro de la Provincia de Buenos Aires (en adelante FACSOUNICEN), y fueron algunos investigadores del área de la historia y la arqueología (prehistórica e industrial) quienes asistieron en la elaboración de los guiones, aportando datos científicos producto de sus investigaciones e imágenes representativas que lo ilustren. En el marco de dicho acuerdo con la FACSO-UNICEN también se incluyó la elaboración de un relevamiento de las opiniones del público visitante sobre la exhibición, a cargo del Programa Interdisciplinario de Estudios del Patrimonio (PATRIMONIA), que cuenta con experiencia en la investigación de las significaciones sociales en contextos de exposiciones museográficas (Conforti 2012; Chaparro et al. 2013; Conforti et al. 2017, Conforti et al. 2018).

En este trabajo se presentan los resultados del estudio

4 En adelante se usará de manera indistinta "ADN" o "Raíces Mineras" para referir a la exposición presentada.

5 Presentación de la exhibición disponible en la web municipal: https:// www.olavarria.gov.ar/adn-raices-mineras/ realizado en el contexto de dicha exhibición titulada "ADN, Raíces Mineras", los cuales permitieron identificar las percepciones y opiniones de los visitantes con respecto a la muestra. Su importancia radica en la producción de nuevos saberes sobre la cultura local, a partir de las diversas valoraciones que la propia población manifiesta en relación a esta propuesta de patrimonialización. Cabe destacar, en primer lugar, que el guión museográfico ha sido elaborado íntegramente por personal de la Secretaría de Desarrollo Económico local empleando para ello algunos materiales aportados por especialistas de las ciencias sociales. En segundo lugar, señalar que nuestro estudio involucra aspectos vinculados con la historia, la identidad, el sentido de lugar y actividades de la vida cotidiana de las comunidades destinatarias de la muestra. En este sentido, el trabajo busca aportar al conocimiento sobre las opiniones, visiones y saberes acerca del patrimonio cultural olavarriense desde la perspectiva de los visitantes a una exhibición. Asimismo, se analiza y discute este caso y lo discute en el marco de las tensiones que actualmente existen entre la clásica activación verticalista de un repertorio patrimonial ("de arriba a abajo") y las propuestas emergentes y superadoras, de corte inclusivo y participativo, en las cuales la comunidad involucrada es protagonista y adquiere un rol activo en todas las etapas del proceso de puesta en valor de sus patrimonios.

\section{La exhibición}

La muestra itinerante "ADN Olavarría. Raíces Mineras" tuvo una única y breve presentación pública ya que estuvo montada sólo durante una semana (del 24 al 30 de setiembre de 2018), en el edificio municipal "Casa del Bicentenario". Durante los primeros cinco días (de lunes a viernes) abrió sus puertas exclusivamente para visitas escolares -del nivel primario y secundario- que eran previamente reservadas y contaban con el servicio de guía a cargo del personal del área de Museos de la Municipalidad. Al culminar las visitas se les hacía entrega de materiales didácticos, con información sobre los contenidos de la muestra para su tratamiento en el aula. Durante ese período se acercaron 14 instituciones escolares procedentes de la ciudad cabecera del partido, que sumaron 850 estudiantes.

El día sábado 29 de septiembre se realizó la inauguración oficial. Se trató de un evento cerrado al que se asistía sólo con invitación personal. Así, con un marco de público de 200 personas se procedió a efectuar un reconocimiento a actores vinculados con el sector minero local (i.e. empresarios y obreros, activos y en retiro). Finalmente, durante la jornada del domingo 30 se abrió la exhibición al público en general de manera gratuita y en esa oportunidad se registró una asistencia de 450 personas ${ }^{6}$.

6 Los datos de la asistencia a los diferentes momentos de la exhibición son de carácter público, extraídos del portal de Radio Olavarría: https://lu32.com.ar/nota/66916/importante-convocatoria-en-adnolavarria-raices-mineras 


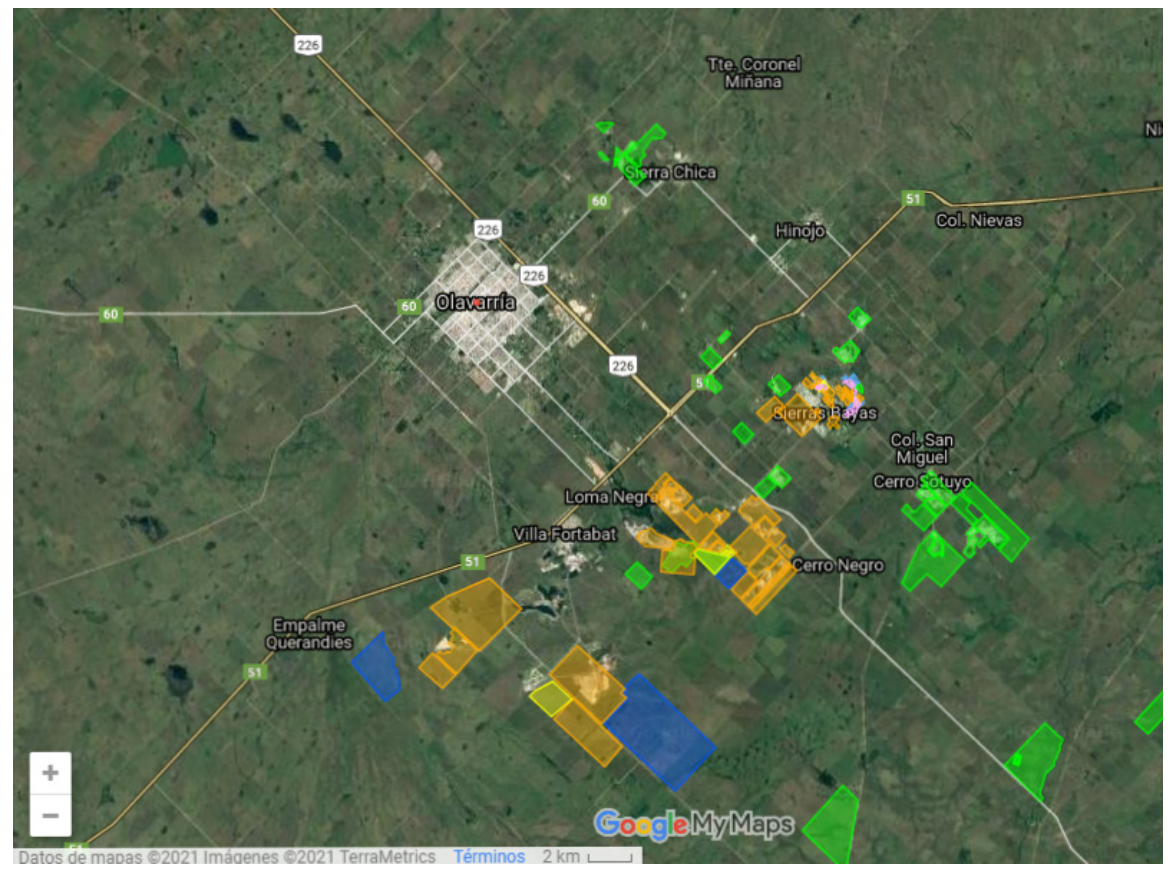

Figura 2. Mapa vista aérea del Área Minero del Partido de Olavarría. Fuente: Subsecretaría de Minería de la Provincia de Buenos Aires: https://www.google.com/maps/ d/u/0/viewer?mid=1aYEnUp2Ekrha3C25IA1 xvaamxI1 kZIN\&II=$37.30556685715162 \% 2 \mathrm{C}$ $60.0419375 \& z=6$

Figure 2. Aerial view map of the Mining Area of the Olavarria district. Source: Subsecretariat of Mining of the Buenos Aires Province: https://www.google.com/maps/ d/u/O/viewer?mid=1aYEnUp2Ekrha3C25IA1xvaamxI1 kZIN\&II=$37.30556685715162 \% 2 \mathrm{C}$ $60.04193758 z=6$

La muestra se presentó principalmente en paneles infográficos y fue complementada con la inclusión de otros recursos expositivos tales como realidad virtual (a través de lentes 3D), exposición de piezas del Museo Municipal de la Piedra "Emma Occhi" (de la localidad de Sierra Chica) y herramientas de hierro empleadas para la extracción y procesamiento artesanal de la piedra (Figura 3).

La jornada de apertura al público en general fue acompañada con actividades culturales que incluyeron la demostración del modelado en arcilla -extraída de la zona serrana- sobre mosaicos murales, a cargo del Taller de Casa de Helen y la talla en piedra realizada por el Taller de Picapedreros y Escultores, así como shows de música en vivo y puestos de venta con diferentes menús gastronómicos.

La exhibición se montó sobre paneles móviles y el guión giró en torno al uso histórico de la piedra como recurso natural del partido de Olavarría (Figura 4). Se partió desde la utilización de las rocas locales por parte de los primeros grupos humanos que habitaron el territorio, quienes las buscaban por su versatilidad para construir diversos instrumentos de piedra. Posteriormente, se describe la minería artesanal desarrollada con el aporte inmigrante europeo de fines del siglo XIX y comienzos del XX. Se enfatiza de manera especial el papel que jugaron las familias pioneras en la producción de la cal, así como en el trabajo de la piedra. Finalmente, se relata la etapa de la industria cementera a gran escala, que se da a partir 1920 y que generó un modelo fabril con villa obrera que se replicó en varias localidades del partido. El guión concluye con la importancia de los minerales extraídos de Olavarría que son rocas de aplicación con un vasto impacto en la vida cotidiana, así como la trayectoria y envergadura actual de la industria cementera y minera y su significación e impacto en la economía regional (ver Conforti et al. 2020:12).

En la historia narrada a través de los sucesivos paneles primó el texto complementado con imágenes. En los dos primeros se utilizaron dibujos originales realizados por una dibujante local y mapas elaborados con información arqueológica para representar las escenas referidas al uso indígena de los recursos y su localización. En los restantes, se sumaron las fotografías de archivo cedidas por investigadores de la UNICEN, familias pioneras de la minería, empresas locales del rubro y el Archivo Histórico Municipal.

Las actividades en donde se empleó realidad virtual consistían en filmaciones en $4 \mathrm{k}$ que permitían, a través de la utilización de cascos, apreciar diferentes escenas actuales del proceso de extracción y producción minera local, tales como el momento en que se efectúa una voladura de frentes de cantera a cielo abierto o el transporte de materia prima desde un camión volquete.

\section{Aspectos conceptuales y metodológicos}

\section{La relación del patrimonio y la comunicación}

Puede afirmarse que existe una relación dialéctica entre la comunicación y el patrimonio cultural. En primer lugar, porque el patrimonio cultural en tanto proceso de construcción social, comunica las ideas, los valores y las memorias que determinados grupos intentan preservar como parte de su identidad (Prats 2000, 2007; García Canclini 1999; Rosas Mantecón 1998). En segundo lugar, porque la comunicación, en sus distintos formatos, es 


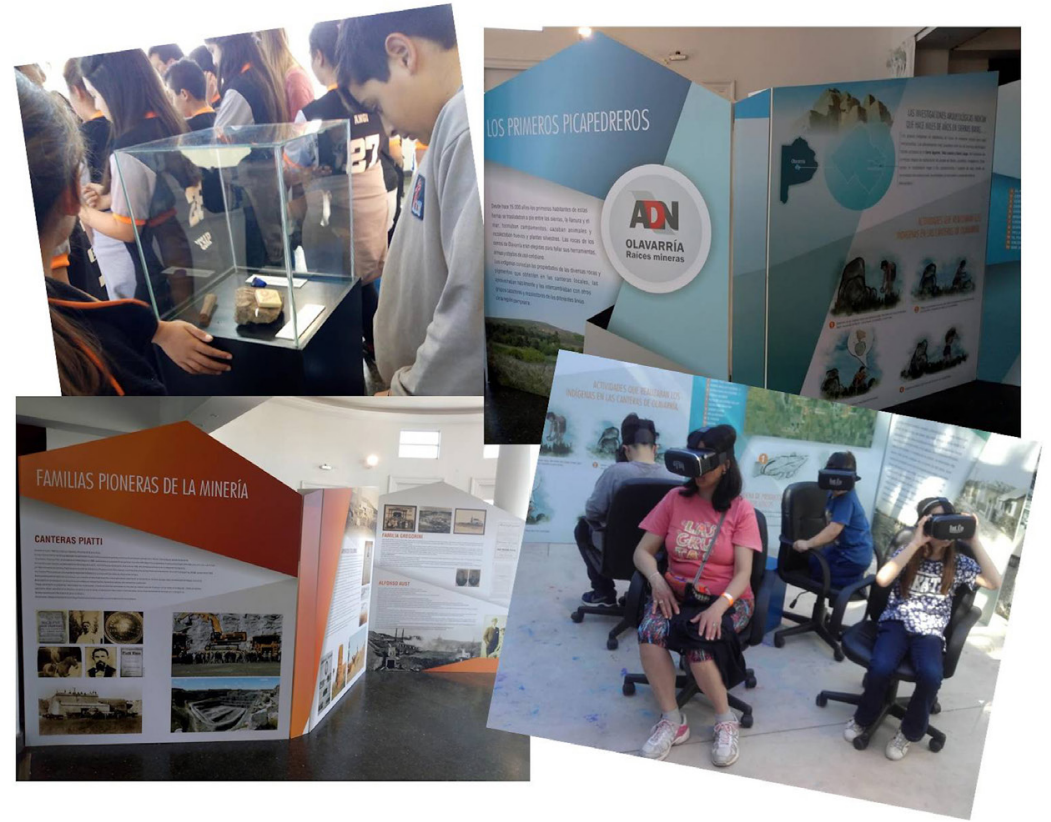

Figura 3. I mágenes representativas de la exposición ADN. Fuente: Autoras.

Figure 3. Representative images of the DNA exposure. Source: Authors.

el modo a partir del cual se transmite, se divulga y se conserva el contenido cultural de una comunidad entre las personas y las generaciones.

Asimismo, se puede plantear un vínculo estrecho entre la comunicación intencional del patrimonio y la educación, tanto sea en contextos de enseñanza formal, como informal o no formal. Según Gutiérrez Pérez (2012)

"la comunicación destinada a promover el conocimiento del patrimonio adquiere un valor educativo en la medida en que repercuta en la construcción de la identidad individual y grupal, ayudando a la gente a reconocerse a sí misma a través de una mayor comprensión del entorno que la rodea; favorezca el desarrollo de actitudes de respeto y conservación del patrimonio y promueva el aprendizaje de conceptos y la construcción de conocimientos relacionados con el
Patrimonio Natural y Cultural" (p. 288)

Cabe destacar que estos procesos giran en torno a un concepto del patrimonio como un "legado" vivo, siempre en construcción y expuesto a la mirada renovada del público, de acuerdo con los diversos significados, lecturas, valoraciones e intereses. En este sentido, no puede pensarse la interpretación del patrimonio sin el público. Por ello, cuando se trata de acciones de puesta en valor a través de exhibiciones, se busca comprender la experiencia de la visita y analizar las múltiples facetas de las que puede estar provista. Se consideran aspectos tan diferentes como complementarios, los cuales remiten a la dimensión cognoscitiva, estética, así como a las relaciones de comportamiento, lúdicas y emocionales (ICOM 2011), y también a las dimensiones simbólicas que indagan sobre creencias, conceptos y representaciones de los visitantes (Poli y Houbart 2014). Estos intereses no son excluyentes
Figura 4. Imágenes representativas de la exposición ADN. Fuente: Autoras.

Figure 4. Representative images of the DNA exposure. Source: Authors.
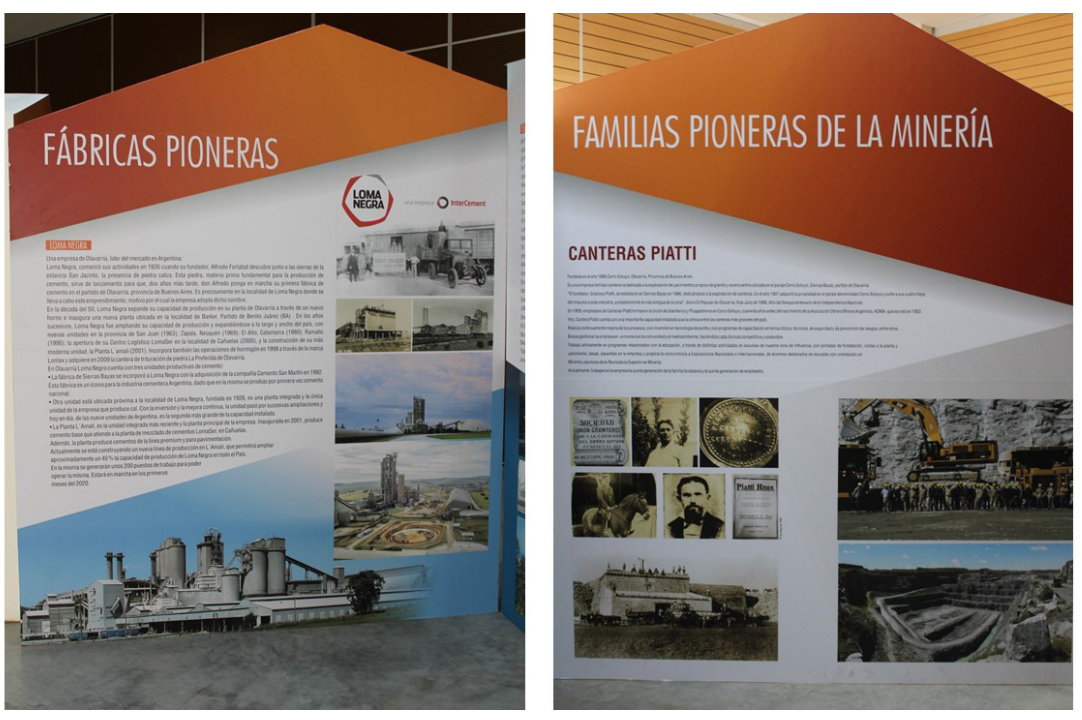
y variarán según los objetivos de la investigación y el contexto institucional en el que se enmarquen (Bialogorski y Reca 2017). En la actualidad se asume que la necesidad de conocer a los visitantes en su diversidad constituye una herramienta indispensable de gestión cultural.

En ese marco, se asume en este trabajo una perspectiva del público como el principal protagonista de la exposición, es decir como un agente activo que participa, de manera crítica y reflexiva, superando la pasividad de espectador que se reduce a la contemplación y el consumo, para convertirse en intérprete del patrimonio $y$, en consecuencia, del mensaje que brinda la muestra (Navarro y Tsagaraki 2010).

\section{El abordaje metodológico del caso ADN}

Para la realización de este estudio se optó por una perspectiva metodológica cualitativa (Della Porta y Keating 2013), cuya estrategia no se reduce tan sólo al uso de ciertas técnicas en el marco de un enfoque de estudio de caso, sino que las excede (Bonvillani 2020). Como un proceso de interpretación de la realidad social que, en términos de Noya Miranda (1999), supone el principio de inclusión del observador en la observación, la conciencia de que lo observado es construido por él, lo que implica la existencia de una mirada situada de quien conoce y nos demanda, en la práctica, a mantener una actitud permanente de autorreflexión. Es por ello que lo "cualitativo" no es equivalente al uso de una técnica, sino que remite a una forma particular de posicionarse frente a la realidad e intentar habitarla, en tal sentido, la disposición hacia la crítica es un aspecto central (Bonvillani 2020).

Tal y como sostiene Mikel Asensio (2017) "no hay que confundir el método con las limitaciones de una técnica, y menos aún la técnica con las limitaciones en su aplicación, por habituales que sean" (p. 8). Es por ello que este estudio se basa por un lado en la técnica de observación (Guber 1991), que incluyó la participación durante la presentación pública de la muestra (realizada por un solo día), y además un rol activo en constante interacción con los organizadores en la etapa del diseño y montaje de la misma. Se la recorrió durante las jornadas de visitas escolares y en la inauguración oficial, además se entrevistó a los guías, organizadores y colaboradores, construyendo así un corpus de información sobre la muestra que luego constituyó un insumo importante en la elaboración de la propuesta de interpelación al público. Por otra parte, se aplicó una encuesta de interacción directa con los visitantes con el objetivo de conocer sus opiniones y valoraciones (Kottak 1993). Cabe aclarar que el uso de este tipo de cuestionario en el marco de una investigación cualitativa sobre una exhibición no está vedado, ya que el mismo no persigue fines estadísticos y permite relevar diversas variables, tales como las más sencillas características sociodemográficas, las preferencias ante la exposición, satisfacción, identificación, entre otras. En este caso se aplicó un cuestionario que combinó preguntas de tipo semi-estructuradas y abiertas (ver modelo de encuesta Figura 5), a adultos mayores de 18 años seleccionados al azar por las encuestadoras (cuatro investigadoras diferentes fueron responsables del relevamiento), a fin de reducir las respuestas sesgadas. Cabe mencionar que para la sistematización, en el caso de las preguntas abiertas, se confeccionaron categorías para agrupar las respuestas a fin de lograr un mejor análisis de las mismas.

Se recogió así una muestra de 110 encuestas que representó un $24 \%$ de los asistentes del día domingo (única jornada abierta al público en general)7. Este relevamiento aporta indicadores cualitativos respecto de ciertas tendencias generales que son importantes para entender los complejos procesos de comunicación que involucra la exposición "ADN Olavarría. Raíces Mineras".

\section{Resultados de las encuestas a visitantes}

Para la presentación de los principales resultados se seleccionaron cinco ejes que agrupan las preguntas según temáticas afines: a) el primero de ellos se orienta a reconstruir el perfil sociodemográfico de los visitantes; $b$ ) el segundo recopila la información tendiente a relevar las primeras apreciaciones del público sobre la presentación integral y el montaje de la muestra; c) el tercero permite construir una noción general sobre el conocimiento que poseen los visitantes respecto de los temas que la misma aborda; d) el cuarto eje indaga el grado de satisfacción con el relato presentado y los objetivos de la exhibición; e) finalmente se incluye un grupo de preguntas abiertas para que los encuestados viertan libremente sus opiniones sobre "ADN Olavarría". Cabe destacar que las consignas incluidas en el quinto eje son transversales a los cuatro anteriores, es decir que los completan y complementan.

a) Respecto de las características sociodemográficas de los encuestados podría decirse, en general, que fue equitativo el número de mujeres (57) y varones (50), aunque variaron las edades. El cuestionario fue completado por 20 personas de entre 18 y 30 años, 25 de entre 31 y 40, 23 de entre 41 y 50, 18 de entre 51 y 60; 11 de entre 61 y 70, y 10 de más de 70 años. Puede evidenciarse que el grupo más representado corresponde con las franjas etarias de entre $31 \mathrm{y}$ 40 , y 41 y 50 años, mientras que los que menos participaron fueron los adultos mayores de 70 .

De toda la muestra, un total de 98 son residentes de la ciudad de la Olavarría, cinco de Sierras Bayas, dos de Hinojo (ambas localidades olavarrienses), dos de la Ciudad Autónoma de Buenos Aires y uno de la ciudad vecina de Azul. Se caracterizan por poseer distintas ocupaciones, dentro de las que destacan las de empleados (41);

7 Los resultados de este estudio fueron entregados a la Municipalidad de Olavarría a través de un informe técnico (Informe 2019). 


\section{MUESTRA “ADN, RAICES MINERAS” ENCUESTA PARA VISITANTES}

(Los resultados obtenidos serán utilizados para investigaciones científicas)

ANONIMA. Adultos mayores de 18 años

\begin{tabular}{|c|c|}
\hline Género: & Edad: \\
\hline Ocupación/profesión: & Lugar de Residencia: \\
\hline \multicolumn{2}{|c|}{$\begin{array}{l}\text { - Califique los siguientes aspectos de la muestra. Tenga en cuenta que } 1 \text { es el menor valor y } 5 \\
\text { el máximo: }\end{array}$} \\
\hline \multicolumn{2}{|c|}{ 1. Valoración global de la visita: $1-2-3-4-5$} \\
\hline \multicolumn{2}{|c|}{ 2. Valoración del diseño de los paneles: $1-2-3-4-5$} \\
\hline \multicolumn{2}{|c|}{ 3. Valoración de la información de los paneles: $1-2-3-4-5$} \\
\hline \multicolumn{2}{|c|}{ 4. Valoración de la exhibición de materiales: $1-2-3-4-5$} \\
\hline \multicolumn{2}{|c|}{ 5. Valoración de la proyección en realidad virtual: $1-2-3-4-5$} \\
\hline ¿Cuánto conocía sob & \\
\hline
\end{tabular}

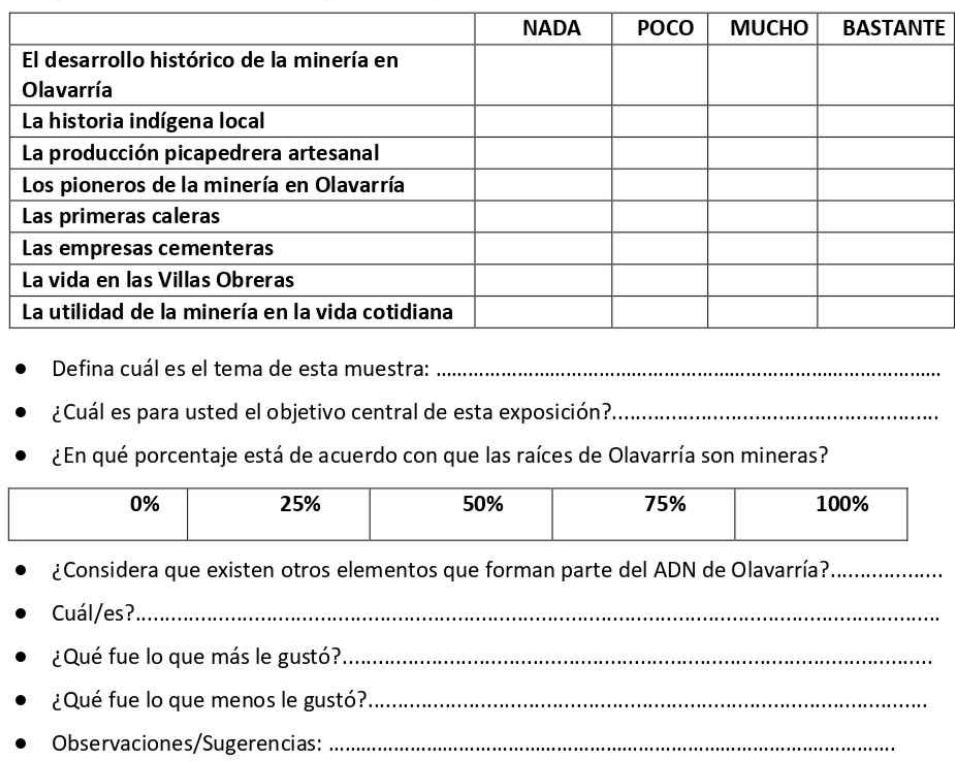

Muchas gracias por su participación

amas de casa (20); profesionales independientes (13); empresarios comerciantes (10) y docentes (7). También participaron jubilados (5) y personas desocupadas (2), tal como indicaron en la grilla. Estas características dan cuenta, por un lado, de que la muestra ha sido visitada en su mayoría por habitantes del partido de Olavarría o ciudades aledañas, con lo cual las opiniones y miradas construidas son principalmente locales; y por el otro, que el público asistente es muy variado en cuanto a su situación laboral. Esto es un aspecto a considerar ya que los resultados vertidos no se corresponden con la mirada de un sólo sector en particular, como pudo haber sido el sector obrero.

b) Ahora bien, para relevar las primeras valoraciones y apreciaciones del público sobre distintos aspectos de la muestra se construyó un cuadro en el que cada encuestado debía seleccionar con una cruz asignando el puntaje de 1 a 5 , siendo 1 el de menor valor y 5 el de mayor, según la
Figura 5. Modelo de encuesta utilizada.

Figure 5. Survey model used.

valoración que le asigne a cada uno de los siguientes aspectos: la muestra de manera global; el diseño de los paneles; la información de los paneles; la exhibición de los materiales y la proyección en realidad virtual.

En cuanto al primer punto, la mayoría (63 encuestados) valora la muestra de modo global con el mayor puntaje, dando cuenta de una apreciación sumamente positiva respecto de la visita. Otros (un total de 28), también otorgan un buen puntaje (de 4) y, en menor medida, pocos visitantes (15) la valoraron con un puntaje de 3 y en un número mínimo con un puntaje de 2 (solo 2 personas). Cabe destacar que ningún encuestado calificó con la menor puntuación (de 1) su experiencia en el lugar.

Con respecto al segundo punto, la valoración sobre el diseño de los paneles, también las respuestas fueron favorables, con un total de 67 personas que otorgaron la mayor puntuación (5) y unas 27 que la calificaron con el siguiente puntaje (4 puntos). En cuanto a la pregunta sobre la información utilizada en los paneles, la mayoría también seleccionó la mejor puntuación (64 personas), aunque -como se indicará más adelante- algunos mencionaron como debilidad la gran de cantidad de texto que estos contenían, cuestión no menor teniendo en cuenta que el objetivo de la exhibición era el de transmitir/comunicar y recordar/conmemorar los principales hitos y acciones -históricas y presentesvinculadas con la identidad del partido. Con respecto a la cuarta dimensión, la valoración de la exhibición de los materiales a través de las vitrinas, la calificación también fue positiva, con un total de 65 personas que otorgaron la mayor puntuación y un porcentaje decreciente que la valoró con menor puntaje ( 26 personas con 4,12 con 5 y unos pocos con 3 y 2 puntos).

Finalmente, con respecto al último ítem de esta primera parte de la encuesta relativo a las calificaciones asignadas al uso de la realidad virtual, se destaca que muchos no contestaron la pregunta (un total de 30) y 4 explicaron que no la vieron o no la usaron. Dentro de las respuestas 
afirmativas, se observa que la realidad virtual gustó, ya que un total de 57 personas la valoraron con una muy buena calificación. De manera complementaria a la información obtenida a través del cuestionario, se pudo observar la atracción que este formato despertó principalmente en los más jóvenes que esperaban su turno para visualizar, a través de filmaciones, el proceso de extracción de la piedra en las canteras locales. Recuperar información sobre estos elementos de interés resulta útil para pensar, a posteriori, en propuestas de comunicación del patrimonio local más dinámicas e interactivas, que permitan reemplazar, por ejemplo, los textos largos y descriptivos que pueden resultar tediosos o directamente no ser leídos. En rasgos generales, los distintos puntos resaltados en esta parte de la evaluación son estimados de manera positiva por la mayoría de los visitantes, quienes coinciden en que la muestra, en sus diversos aspectos, merece la máxima calificación.

c) Por otra parte, la encuesta también incluía preguntas tendientes a indagar sobre el conocimiento que los visitantes tenían sobre distintos aspectos de la exhibición. Uno de ellos (el primero) consistió en examinar cuánto se conocía sobre el desarrollo histórico de la minería en Olavarría, lo que dio como resultado que la mayoría (un total de 48 personas) conoce "poco" sobre el tema, aunque otros reconocen que saben "bastante" y "mucho" al respecto (21 visitantes en cada caso). Pese a ello se destaca un número importante que respondió no conocer "nada" sobre la temática (17 personas en total), lo cual resulta un dato a considerar sobre todo al momento de aseverar la raíz histórica que tiene la minería en esta región (Figura 6).

El segundo aspecto abordado fue la historia indígena local para lo cual la mayoría de los encuestados indicó conocer "poco" (56 encuestados) y en segundo lugar "nada" (21). Las opciones "mucho" y "bastante", alcanzaron un total de 16 y 14 respuestas respectivamente, siendo inferiores en cantidad a las que reconocieron el desconocimiento

Figura 6. Conocimiento sobre la minería (en porcentaje).

Figure 6. Knowledge about mining (in percentage).

\section{Conocimiento sobre la historia de la minería}

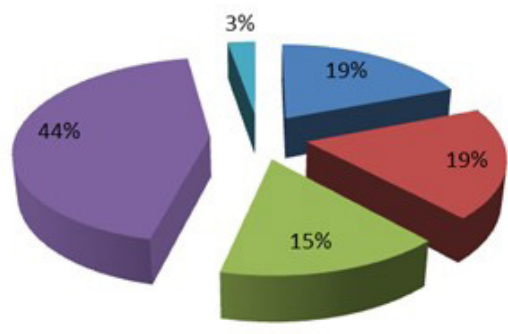

\section{Conocimiento sobre la historia indígena}

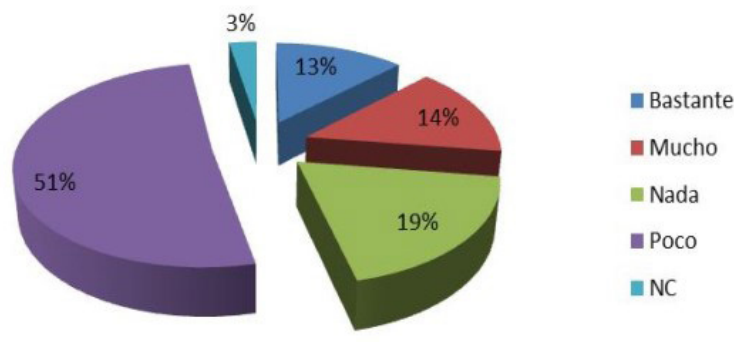

Figura 7. Conocimiento sobre la historia indígena (en porcentaje).

Figure 7. Knowledge about indigenous history (in percentage).

sobre el tema (Figura 7).

La producción picapedrera artesanal fue otro de los aspectos consultados. La mayoría de los encuestados (54) respondió conocer "poco" y otros respondieron no conocer "nada" al respecto (25). En tercer lugar, se ubicaron quienes contestaron que saben "mucho" (16) y en cuarto lugar los que indicaron que conocen "bastante" (14), pero se destaca la menor proporción de esta última opción frente a las anteriores. También se les preguntó sobre los pioneros de la minería en Olavarría, donde nuevamente las respuestas que indican "poco" (49) y "nada" (26) superaron en número a las que dicen conocer "mucho" (19) y "bastante" (11). Estos resultados basados en el mínimo -o nulo- conocimiento que expresan los visitantes encuestados sobre los comienzos del trabajo ligado con los recursos naturales de la región, previo a la creación de las industrias, es diagnóstico. En efecto, denotan la falta de un vínculo histórico y del reconocimiento de los procesos complejos -los cuales incluyen la historia indígena- que condujeron a los actuales alcances e impactos que tiene la minería local, no sólo en términos económicos, sino también sociales, en torno a la configuración de las formas de vida de las poblaciones del área.

En el mismo sentido, y con respecto a las primeras caleras, una gran parte de los encuestados (54) indican que conocen "poco" y en segundo lugar admiten no conocer "nada" sobre estas (21), pese a ser un rasgo característico y distintivo de las localidades olavarrienses. No obstante, no ocurre de igual modo con las empresas cementeras, ya que si bien un amplio número de encuestados (41) admiten saber "poco" acerca de las mismas, en mayor grado responden de manera positiva, afirmando conocer "mucho" (32) y "bastante" (28). En esta oportunidad muy poco (solo 6) eligieron la opción "nada" para referir a su nulo conocimiento sobre el tema. Ello puede deberse a que el desarrollo económico local está atravesado, en múltiples dimensiones, por la industria del cemento 


\begin{tabular}{|c|c|c|c|c|c|c|}
\hline & Nada & Poco & Mucho & Bastante & No contesta & \multirow{9}{*}{$\begin{array}{l}\text { Tabla 1. Resultados de las } \\
\text { encuestas con opciones } \\
\text { múltiples. } \\
\text { Table 1. Results of the multiple } \\
\text { choice surveys. }\end{array}$} \\
\hline $\begin{array}{l}\text { El desarrollo histórico de } \\
\text { la minería en Olavarría }\end{array}$ & 17 & 48 & 21 & 21 & 3 & \\
\hline La historia indigena local & 21 & 56 & 16 & 14 & 3 & \\
\hline $\begin{array}{l}\text { La producción } \\
\text { picapedrera artesanal }\end{array}$ & 25 & 54 & 16 & 12 & 3 & \\
\hline $\begin{array}{l}\text { Los pioneros de la minería } \\
\text { en Olavarría }\end{array}$ & 26 & 49 & 19 & 11 & 5 & \\
\hline Las primeras caleras & 21 & 54 & 18 & 15 & 2 & \\
\hline Las empresas cementeras & 6 & 41 & 32 & 28 & 3 & \\
\hline $\begin{array}{l}\text { La vida en las villas } \\
\text { obreras }\end{array}$ & 22 & 40 & 24 & 22 & 2 & \\
\hline $\begin{array}{l}\text { La utilidad de la minería } \\
\text { en la vida cotidiana }\end{array}$ & 10 & 30 & 31 & 38 & 1 & \\
\hline
\end{tabular}

y gran parte de la población es empleada en trabajos relacionados a esta. Es claro el conocimiento actual sobre las empresas cementeras y su trayectoria relativamente reciente, aunque muchos desconozcan su historia y los procesos que condujeron a su auge y circunstancia contemporánea.

Los últimos dos ítems se centraron en indagar sobre el conocimiento relacionado con las villas obreras y la utilidad de la minería en la vida cotidiana. En el primer caso, un gran numero de encuestados (40) encuestados respondió conocer "poco" de las villas, aunque varios (24) admitieron saber "mucho" y otros, en igual cantidad, afirman conocer "bastante" (22) y "nada" (22). En el segundo caso, las respuestas evidencian que los encuestados conocen en su mayoría "bastante" (38) y "mucho" (31) sobre la utilidad de la minería, en un orden decreciente de respuestas para la opción "poco" (30) y "nada" (10). Esto se corresponde con las respuestas mencionadas más arriba sobre las empresas cementeras y su funcionamiento contemporáneo en la actividad económica regional (Tabla 1).

Cabe destacar la disparidad en los saberes de los encuestados, lo cual se vuelve significativo para pensar que el interés en este tipo de exhibición provino, tanto de parte de conocedores del tema e incluso habitantes involucrados en la historia y la producción minera actual, como de un público asistente que está alejado de la realidad de la minería y su vida asociada. Este debería ser un punto a favor para promover y comunicar, a partir de distintas propuestas, los saberes que son comunes al devenir histórico de Olavarría y toda la zona; y que exceden el vínculo más particular que algunos pobladores puedan tener con la actividad. Por otro lado, la diversidad de los asistentes se podría asociar también al hecho de que la performance que se utilizó para la puesta en escena de la muestra atrajo la atención de los ciudadanos que circulaban por la zona de manera casual y recreativa. Es lógico pensar que ello pudo haber ocurrido teniendo en cuenta que la exhibición se realizó un día domingo en un lugar público altamente transitado de la ciudad y se asoció a otras propuestas que se efectuaron en espacios de esparcimiento público, al aire libre, como espectáculos musicales, puestos de comida, escultores en escenas y artistas modelando arcilla, entre otras.

d) El cuarto eje de preguntas estuvo destinado a indagar el grado de satisfacción respecto del relato de la exhibición. Una de las consignas consistió en responder en qué porcentaje estaban de acuerdo con la afirmación de que las raíces de Olavarría son mineras. La mayoría respondió que estaban de acuerdo en un $100 \%$ (en total 47 personas), y en un orden decreciente sostuvieron que lo compartían en un $75 \%$ (42), en un 50\% (16), en un $25 \%$ (3) y en un $0 \%$ (2). Por otro lado, se interrogó respecto a si consideraban la existencia de otros elementos que forman parte del ADN de Olavarría. En principio, varios respondieron que "sí" (42), otros que "no" (20) y un número considerado (48) "NS/NC". Este podría ser un indicador que permite inferir el grado de desconocimiento, desinformación o desinterés que pueda haber al respecto. Para aquellos que respondieron que "sí" agregaron las "actividades rurales" (23) y otros aludieron al "automovilismo" (5), señalando a los hermanos Emiliozzi8; "Ios inmigrantes" (5); "los pueblos originarios" (5); "el comercio/industria" (4), el "ferrocarril" (3) y el "arroyo Tapalqué" (3).

8 Los hermanos Emiliozzi, Dante y Torcuato, fueron pilotos y mecánicos del Turismo Carretera de los años 1950 y 1960, convirtiéndose en ganadores de 42 carreras y cuatro campeonatos argentinos de Turismo Carretera entre 1962 a 1965. Si bien nacieron en la ciudad de Buenos Aires, su familia -de origen Italiano- se instaló definitivamente en 1923 en la ciudad de Olavarría, donde desarrollaron su oficio de mecánicos en el taller de su padre y su carrera como piloto (Dante) y acompañante (Torcuato) que los llevó, con sus triunfos, a obtener un gran reconocimiento y estima por parte de los habitantes de Olavarría y a ser identificados como parte de la historia de la localidad. Actualmente, en la ciudad se encuentra un museo inaugurado por el gobierno municipal en el 2013 en su honor y memoria y, asimismo, el autódromo local se denominó oficialmente "Hermanos Emiliozzi". 
Las preguntas siguientes fueron: ¿qué fue lo que más le gustó? y ¿qué fue lo que menos le gustó? de la muestra. En el primer caso, varias personas (22) respondieron que "todo" y en igual número de asistentes (22) también se resaltó el "taller de escultura en vivo". Varios encuestados destacaron "la realidad virtual" (13) y los "materiales exhibidos" (12); y otros mencionaron "la cartelería y los paneles" (6); la "historia de la minería" (6), haciendo hincapié en lo indígena, las fábricas, la piedra y las canteras; y finalmente "el trabajo en cerámica del artista local Mauricio D’amico y la escuela municipal" (5).

Respecto de lo que menos les gustó, muchos no contestaron (74) y otros (17) respondieron que "nada". Esto evidencia que la mayoría se sintió a gusto con la exhibición o, al menos, no tiene cuestiones importantes a mencionar en este aspecto. Sin embargo, suele suceder que los encuestados no siempre se animan a expresar su desagrado debido a que impera una actitud de responder acorde a lo que se cree que se desea sea respondido, por lo que no debe descartarse que cierto grado de deseabilidad social haya podido operar, al menos en algún porcentaje de estas respuestas. Cabe explicitar, sin embargo, que entre los que respondieron que hubo aspectos que le gustó menos, hicieron mención a "los materiales expuestos", el "poco material", "la música fuerte", el "lugar" donde se desarrolló la muestra, los "paneles" con mucha información para leer; la organización del evento (sin especificar a qué cuestiones puntuales hacían referencia) y la poca difusión.

e) Por último, el quinto eje de preguntas corresponde a las consignas abiertas que obtuvieron respuestas múltiples, cuestión que requirió generar una serie de categorías abarcativas. La primera consigna fue definir cuál era el tema de la muestra. La mayoría de los encuestados respondió "la minería" (54) y varios también aludieron a la "historia de la minería" (24), enfatizando en el recorrido que la muestra presentaba de dicha producción a lo largo del tiempo. Cabe destacar que algunas personas (15) no contestaron esta consigna y otros pocos aludieron al "oficio artesanal" (9), la "piedra" (4), las "canteras" (1) y la "piedra y la minería como patrimonios" (3). Esta última categoría se identificó por separado porque los encuestados apelaron en sus respuestas a lo patrimonial, asociándolo a los recursos mineros locales, lo cual merece ser destacado, pese a que fueron mínimas las respuestas en este sentido.

Otra de las consignas consistió en indagar acerca de cuál era el objetivo central de la exposición. Las respuestas fueron muy similares para lo cual se crearon sólo dos categorías. La primera, "dar a conocer la temática", que incluye que el objetivo de la muestra fue para la mayoría (un total de 93 encuestados) informar sobre varios aspectos relacionados con la minería, la historia, los recursos locales, el trabajo y la cultura. La segunda categoría fue "revalorizar el saber artesanal, la identidad e historia local", incluyó a pocos encuestados (solo 9) encuestados que reconocieron en la muestra una intención de poner en valor aspectos más vinculados a los grupos humanos, sus saberes y el recorrido histórico a través del cual se fue construyendo parte de la identidad olavarriense.

Finalmente, el cierre del cuestionario dio lugar a que los encuestados pudieran hacer sus observaciones/ sugerencias sobre la experiencia de la visita. En este último punto, varias fueron las apreciaciones positivas (23) de personas que enfatizaron en lo "lindo" e "interesante" de la exhibición, así como en la necesidad de "repetir" eventos de estas características, haciendo hincapié fundamentalmente en el trabajo en piedra y la realidad virtual. También hubo algunas apreciaciones negativas (19 en total), las cuales se centraron en aspectos que se debían mejorar como "la visita guiada" la "organización", una "mayor difusión", "la información sobre los pueblos originarios", "los folletos" y la "elección del lugar", donde se resaltó críticamente la disposición de los paneles y la falta de materiales en exposición. Por último, también se hizo referencia a que la muestra podría mejorarse con mayor interactividad e impacto visual. Cabe destacar que varias personas (63) personas no contestaron esta consigna.

\section{Discusión y conclusiones}

El objetivo de la Secretaría de Desarrollo Económico municipal fue realizar una actividad que revalorizara la producción minera local en el contexto de las celebraciones por el centenario del primer despacho de cemento, para lo cual se desarrolló la primera edición de la Exposición "ADN Olavarría. Raíces Mineras". La finalidad de la muestra fue posicionar la actividad como un referente identitario, por lo que se focalizó en la profundidad y el desarrollo histórico de la explotación de los recursos disponibles en las canteras de la región. A partir de ello, y de los resultados obtenidos en el relevamiento realizado sobre la opinión de sus visitantes, se identifican los siguientes ejes de discusión: 1) la interpretación del patrimonio desde la museografía, 2) la valoración del aporte de los investigadores y especialistas, 3) la activación verticalista de un repertorio patrimonial, para finalmente discutir sobre 4) el rol de los investigadores como activadores de procesos de puesta en valor del patrimonio cultural local.

En relación con el eje 1: la interpretación del patrimonio (Maragliano 2010) y a nivel museográfico, la muestra cumplió con el objetivo de presentar e informar sobre la actividad minera en Olavarría, ya que casi el $90 \%$ de los encuestados identificó que la misma "dio a conocer la temática", especialmente su devenir histórico. No 
obstante, entre el $60 \%$ y el $75 \%$ de los visitantes mencionó saber "poco" o "nada" sobre la actividad artesanal picapedrera y los pioneros, el aprovechamiento indígena de las canteras y la instalación de las primeras caleras. Solo los temas más cercanos en el tiempo como las villas obreras y las empresas cementeras fueron los más conocidos por los visitantes. Con respecto a la forma de presentar la información, aunque fue en general bien valorada por el público, el mismo identificó algunas disconformidades tales como el espacio donde se llevó a cabo; la gran cantidad de información brindada; el poco aprovechamiento de los dispositivos de realidad virtual (casi el 30\% no lo usó) y la escasa difusión de la exposición como una actividad cultural local.

Es decir que, si bien la muestra cumplió con sus objetivos básicos en cuanto a la difusión de contenidos sobre la producción minera, se considera que para las próximas ediciones podrían tenerse en cuenta algunas de las sugerencias realizadas desde el punto de vista museográfico, tales como ajustar la cantidad de información de los paneles, diseñar formas de presentación más interactivas y repensar otros espacios de exposición.

Hubiera sido aconsejable, además, planificar estrategias comunicacionales más adecuadas para que sea accesible a un público más amplio y diverso, a la vez que ampliar el tiempo de exposición, lo cual podría garantizar una mayor afluencia de visitantes. Asimismo, si se tiene en cuenta que la interpretación patrimonial tiene un segundo objetivo que apunta a promover la evocación de determinados sentimientos y comportamientos (Maragliano 2010), podrían incluirse más dispositivos que apelen a rememorar aspectos susceptibles de movilizar y sensibilizar a los diferentes públicos (por ejemplo, sectores o grupos en términos de género, etnicidad y/o clase, generaciones, etc.) sobre un pasado compartido. También contribuir a motivar actitudes de respeto por la salvaguarda de la historia y la memoria colectiva, así como un mayor involucramiento en acciones de socialización, cuidado y preservación de los bienes culturales comunes.

Con respecto al eje 2, que refiere a la valoración del trabajo científico por parte de los encargados de la gestión municipal, cabe destacar que algunas de las autoras de este trabajo fueron consultadas a fin de completar ciertos vacíos temáticos en el guión original (por ejemplo, el empleo de las rocas de las canteras locales por parte de grupos indígenas a lo largo de miles de años, la formación histórica de las primeras villas, etc.). Pese al aporte efectuado no tuvieron la posibilidad de opinar en relación al relato general de la exhibición, ni respecto de la elección del título de la muestra "ADN. Raíces Mineras". La participación de los especialistas en el proceso de elaboración de la misma fue parcial, a pesar de haber ofrecido su expertise no sólo en relación a los contenidos, sino además en el montaje de exhibiciones, por contar con experiencias previas en esas temáticas, así como en estudios sobre el público local (Chaparro et al. 2017; Endere et al. 2009; Endere et al. 2018). Es por ello que, si bien es importante valorar el acercamiento del gobierno municipal a la Facultad de Ciencias Sociales y el reconocimiento efectuado al aporte y asesoramiento brindado, se considera que este fue acotado y lejos de generar una contribución acorde con todo el potencial disponible. Serias limitaciones de tiempo, personal no especializado afectado a la tarea y directivas que no lograron dimensionar su magnitud, sin duda conspiraron contra el alcance de mejores resultados.

En el eje 3 de discusión, esta propuesta responde a la clásica activación verticalista de un repertorio patrimonial realizado por un gobierno municipal. En este caso son claras las intenciones de reivindicar y reforzar uno de los imaginarios hegemónicos locales en términos ideales y sin conflictos, de corte histórico para Olavarría: la producción minera asociada a la imagen de "ciudad del trabajo" (Gravano 2005). Así, se dejó fuera del espectro otras múltiples dimensiones locales de relevancia para el imaginario colectivo. Sobre esta cuestión, puede observarse que los visitantes en sus respuestas sobre el nombre de la exhibición "ADN", reconocen la relevancia de la producción minera para Olavarría como un aspecto constitutivo, pero también mencionan como importantes otras varias actividades tales como la agropecuaria, comercial y/o deportiva, que le otorgan a la localidad una impronta más diversa.

Es en este sentido cuando propuestas como ADN, de tipo verticalistas, entran en tensión con otras nociones superadoras más recientes, de corte inclusivo y participativo donde la comunidad protagonista adquiere un rol activo en todas las etapas del proceso de puesta en valor de sus patrimonios -y no es concebida tan sólo como mera espectadora-. El caso presentado es un ejemplo más de activación "de arriba a abajo" (García Canclini 1999), donde el gobierno municipal asume que la actividad minera en el partido es parte constitutiva central de la identidad olavarriense y por lo tanto, se atribuye la potestad de ponerlo en valor y la promueve públicamente, exacerbando las figuras empresariales locales así como las familias inmigrantes dedicadas al trabajo minero. Queda claro que se trata de una acción política que apunta a que la comunidad conozca y "valore" esa actividad por sobre otras. De esta manera se advierte:

"toda elección de lo que es -o no es-representativo de una ciudad (su patrimonio, su identidad), es el resultado de procesos en los que intervienen actores sociales e instituciones que tienen el poder y el capital para legitimar determinadas imágenes y sentidos culturales por sobre otros" (Mariano 2020:8).

Justamente es en dicho marco donde la gestión oficial de Olavarría se impone asociada a modelos patrimoniales 
hegemónicos. Esta experiencia da cuenta de una gestión cultural que no logra articular de modo inclusivo y participativo a los diversos sectores o grupos de interés, ni es capaz de aprovechar los recursos humanos formados a nivel local, a fin de poner a disposición del público décadas de investigación sobre la geología, la arqueología, la historia y el patrimonio local; todos ellos vinculados con los recursos mineros de la zona.

En relación al eje 4 de discusión, es necesario destacar que la responsabilidad de la gestión cultural no es exclusiva de los gobiernos, sino que le compete también a los investigadores, quienes debieran -o deberíamosesforzarse por generar espacios de diálogo y proveer estrategias que permitan no sólo asistir con el propio conocimiento disciplinar, sino también recuperar las demandas, intereses, significados y valores de la diversidad de actores locales que forman parte del "pool genético" de Olavarría. Asimismo, al afirmar lo trascendental del rol del "público" -entendido en toda su diversidad- en la producción colectiva del saber en torno del patrimonio cultural (Gianotti García et al. 2015), los investigadores deben asumir la tarea y el compromiso de interactuar con los gestores culturales y con los diversos grupos que integran la comunidad (Castillo Mena 2015).

A modo de conclusión, se espera que la información producida y las reflexiones efectuadas en este trabajo aporten, por un lado, al conocimiento sobre las valoraciones, visiones y saberes acerca del patrimonio cultural olavarriense, a partir del análisis de las opiniones de los visitantes -mayoritariamente locales-. Por otro lado, constituyan un aporte y una invitación a explorar, en el futuro, formas más dialógicas, participativas y sinérgicas para la puesta en común del patrimonio cultural local.

Olavarría, 26 de marzo de 2021

\section{Agradecimientos}

Se agradece a las autoridades de la Secretaría de Desarrollo Económico (Direcciones de Minería y Turismo) y la Subsecretaría de Cultura y Educación de la Municipalidad de Olavarría por permitir la realización de este estudio, así como a todas las personas que aceptaron ser encuestadas y/o entrevistadas. Este trabajo fue realizado en el marco del Programa PATRIMONIA, línea de investigación del Instituto INCUAPA (UE CONICET-UNICEN) y financiado por subsidios de investigación dirigidos por la Dra. María Luz Endere: "Estudio de las significaciones sociales del patrimonio cultural del partido de Olavarría, provincia de Buenos Aires. Propuesta metodológica para su visibilización y salvaguarda" (PIP 106/15 CONICET) e "Investigación, Gestión y Significación Social del Patrimonio Cultural en el Centro de Buenos Aires y Centro-Este de San Luis" (PICT0551/16 ANPCyT).

\section{Bibliografía}

Alfrey, J. y Putnam, T. (1992). The Industrial Heritage: Managing resources and uses. Routledge.

Asensio, M. (2017). Prólogo. En Mirta Bialogorski y María Marta Reta (comps.), Museos y visitantes. Ensayos sobre estudios de público en Argentina (pp. 7-22). ICOM Argentina.

Belini, C. (2009). La industria peronista: 1946-1955: políticas públicas y cambio Estructural. Edhasa.

Bialogorski, M. y M. Reta (Comps.). (2017). Museos y visitantes. Ensayos sobre estudios de público en Argentina. ICOM Argentina.

Bonvillani, A. (2020). El don de la conversación. Preguntar en el proceso de investigación. En Kriger, M. (Dir.), La entrevista virtual y sus claves (pp. 1-22). IDES-virtual.

Castillo Mena, A. (Ed.). (2015). Actas del Segundo Congreso Internacional de Buenas Prácticas en Patrimonio Mundial: Personas y comunidades. Universidad Complutense de Madrid.

Chaparro, MG., Borgo, M., Degele, P. y Vergara, D. (2013). Los estudios de público escolar y la comunicación de la arqueología. Revista del Museo de La Plata. Sección Antropología 13: 459-474.

Chaparro, M.G, Conforti, M.E y Endere, M.L. (2017). Estrategias de comunicación pública de la ciencia para la revalorización del patrimonio. Análisis de caso en Argentina. Revista de Ciencias Sociales (Ve) XXIII: 1 (1): 46-57.

Cingolani, C., L. Hartmann, J. Santos y N. McNaughton. (23 al 26 de Abril de 2002). U-Pb SHRIMP dating of zircons from the Buenos Aires complex of the Tandilia Belt, Río de La Plata Craton, Argentina. [Actas 1 (pp. 149-154)]. 15 Congreso Geológico Argentino. El Calafate, Argentina.

Conforti, M.E.; Lemiez, G.; Giacomasso, M.V. y M.L. Endere. (2020). A cien años del primer despacho de cemento portland en Argentina. Prácticas patrimoniales en el contexto de su celebración. Revista Páginas 12 (30): 1-26. http://dx.doi.org/10.35305/rp.v12i30.446

Conforti, M.E.; Chaparro, M.G.; Degele,P. y Díez Fernández Lomana, J.C. (2018). Visitor profiling at the Museum of Human Evolution of Burgos (Spain). Journal of Science Communication JCOM 17 (04): 1-21.

Conforti, M.E.; Chaparro, M.G.; Mariano, M. y J.C. Díez Fernández-Lomana (2017). "Haciéndonos humanos. Análisis de una exhibición científica en Argentina". Chungara. Revista de Antropología Chilena 49 (1):81-98. 
Conforti, M.E. (2012). El público y el patrimonio arqueológico. El caso de la comunidad de Tres Arroyos en relación con el sitio "Arroyo Seco 2" y la muestra del Museo Municipal "José A. Mulazzi". Revista del Museo de Antropología de Córdoba 5: 131-140.

Della Porta, D. y Keating, M. (Eds.). (2013). Enfoques y metodologías de las ciencias sociales. Una perspectiva pluralista. Akal.

Endere, M. L; Chaparro, M. y M. Conforti. (2018). Making Cultural Heritage Significant for the Public. The Role of Researchers in Encouraging Public Awareness and Local Pride. Public Archaeology, 17, (1), 36-54. https://doi.or g/10.1080/14655187.2018.1499390.

Endere, M, M. G. Chaparro, V. Palavecino y D. Iarritu. (2009). Percepciones y reflexiones sobre el patrimonio cultural de los partidos de Azul, Olavarría y Tandil. En Endere, M.L y Prado, J. L (Eds.), Patrimonio, ciencia y comunidad: su abordaje en los partidos de Azul, Olavarría y Tandil. UNICEN.

García Canclini, N. (1999). Los usos sociales del patrimonio cultural. En Aguilar Criado (Ed.), Patrimonio etnológico. Nuevas perspectivas de estudio (16-33). Consejería de la Cultura, Junta de Andalucía.

Gianotti García, C., Barreiro Martínez, D. y B. Vienni Baptista (2015). Patrimonio y multivocalidad. Teoría, práctica y experiencias en torno a la construcción del conocimiento en patrimonio. Universidad de la República.

Gravano, A. (2005). Palimpsesto urbano: sobre-escritura de huellas diacrónicas de la ciudad imaginada. En Gravano (Ed.), Imaginarios sociales de la ciudad media. Emblemas, fragmentaciones y otredades urbanas. Estudios de Antropología Urbana (pp. 35-49). Red de Editores de Universidades Nacionales, Buenos Aires.

Guber, R. (1991). El salvaje metropolitano. Legasa.

Gutiérrez Pérez, R. (2012). Educación Artística y Comunicación del Patrimonio. Arte, Individuo Y Sociedad, 24(2): 283-299. https://doi.org/10.5209/rev_ARIS.2012. v24.n2.39035

ICOM International Committee for Museology (23 al 26 de Octubre de 2011). The Dialogic Museum and the visitor experience Actas del 34 ICOFOM Annual Symposium. Tapei and Koashiung, Taiwan.

ICOMOS- TICCIH (2003). Carta de Nizhny Tagil sobre el patrimonio industrial, TICCIH-ICOMOS, Moscú.

Informe Técnico Secretaría de Desarrollo Local, Municipalidad de Olavarría. (2019). Resultados del estudio de público realizado durante la exhibición itinerante 'ADN, Raíces Mineras'.

Kottak, C. (1993). Antropología. Una exploración de la diversidad humana. McGraw-hill/Interamericana.

Lemiez, G. (2018). Paternalismo industrial y disciplina fabril. El caso de la industria del cemento en la ciudad argentina de Olavarría, 1940-1970. Revista Cuadernos de Relaciones Laborales 36 (1): 147-165.

Maragliano, M. (2010). Interpretación del Patrimonio: Una experiencia de conocimiento que revela significados. Boletín de la Asociación de Interpretación del Patrimonio 22: 17-20.

Mariano, M. (2020). Entre lo oficial y lo alternativo. Un análisis sobre la diversidad de usos y sentidos del patrimonio y la cultura en una ciudad del centro de la provincia de Buenos Aires. Revista de Antropología del Museo de Entre Ríos 5 (2) (En prensa).

Messineo, P. y M. Barros (2009). Las ocupaciones arqueológicas del Holoceno tardío en la cuenca superior del arroyo Tapalqué (partido de Olavarría). En Endere, M. y J. Prado (Eds.), Patrimonio, ciencia y comunidad. Su abordaje en los partidos de Azul, Olavarría y Tandil (pp. 165-184). UNICEN.

Navarro, Ó. y C. Tsagaraki. (2010). Museos en la crisis: Una visión desde la museología crítica. Museos.es, Revista de la Subdirección General de Museos Estatales 6: 50-57.

Neiburg, F. (1988). Fábrica y Villa Obrera: Historia social y antropológica de los obreros del cemento. Centro Editor de América Latina.

Noya Miranda, F. (1995). Metodología, contexto y reflexividad. Una perspectiva constructivista y contextualista sobre la relación cualitativo-cuantitativo en la investigación social. En J. M. Delgado y J. Gutiérrez (Coords.), Métodos y Técnicas cualitativas de investigación social. Síntesis.

Paz, C. (2009). El desarrollo de la minería en el partido de Olavarría. Su abordaje desde la arqueología industrial. En M.L. Endere y J. Prado (Eds.) Patrimonio, ciencia y comunidad. Su abordaje en los partidos de Azul, Olavarría y Tandil (pp. 283-302). UNICEN.

Poli, M. y Houbart, D. (2014). El impacto del discurso museográfico en los visitantes de la exposición 'El arte italiano y la metafísica. La época de la melancolía. 19121935'". En: J. Eidelman, M, Roustan\&B, Goldstein (comp.), El museo y sus públicos. El visitante tiene la palabra, (pp.105-21). Editorial Ariel.

Prats, LL. (2000). El concepto de Patrimonio Cultural. Cuadernos de Antropología Social, 11, 115-135. https:// 
doi.org/10.34096/cas.i11.4709

Prats, LL. (2007). Antropología y Patrimonio. Editorial Ariel.

Rosas Mantecón, A. (1998). El patrimonio cultural. Estudios contemporáneos. Presentación. Alteridades, 8
(16), 3-9. https://doi.org/10.24275/alte.v0i16

Secretaria de Desarrollo Económico, Dirección de Minería. (2018). Desarrollo de la Minería en el Partido de Olavarría. Material didáctico para escuelas. Municipalidad de Olavarría. Ms. 